\title{
Methodology of the micro-computer tomography on foraminifera
}

\author{
Ágnes Görög, Balázs Szinger, Emőke Tóth, János Viszkok
}

\begin{abstract}
Research focused on the methodology of the micro-CT device in the foraminifera studies reviewing its advantages and limits. First, the procedure of stable, oriented and removable fixing of foraminifera, washing residue and cuttings in the device was developed, which is fast, cheap, non-destructive and the sample remains re-usable for further investigation. Moreover, a process was developed for foraminifera investigation (e.g., content, amount, identification, description, illustration) in the shortest and simplest way. In the identification of foraminifera as well as in other microfossils group (e.g., radiolaria) the external and internal characteristics together identified the genera, even the species. Additionally, there are several foraminifera species, which are known only from the rock thin sections. The micro-CT was found to be a unique tool for real 3D microscopy and to be able to present the characteristic morphological features when the free movement, rotation or sectioning of the models of the specimens can be performed by interpretation software. However, the biggest advantage of this method is its non-destructive property, which makes it also capable of measuring valuable materials such as holotypes. The relatively small volume analysed and the lack of specific software developed for different micropalaeontological groups are the limits of this method. This visualization technique gives new perspectives in taxonomical studies and in applied micropalaeontology.
\end{abstract}

Ágnes Görög. Department of Palaeontology, Eötvös University, Pázmány Péter sétány 1/C, Budapest, H1117, Hungary. gorog@ludens.elte.hu

Balázs Szinger. Department of Palaeontology, Eötvös University, Pázmány Péter sétány 1/C, Budapest, H1117, Hungary. szinger.balazs@gmail.com

Emőke Tóth. Research Group for Palaeontology, Hungarian Academy of Sciences-Hungarian Natural History Museum - Department of Palaeontology, Eötvös University, Pázmány Péter sétány 1/C, Budapest, H-1117, Hungary. cypridina1981@yahoo.com

János Viszkok. Central Geo Ltd, Mária út 10, Szolnok, H-5000, Hungary. jviszkok@centralgeo.hu

KEYWORDS: micro-CT; micropalaeontology; 2D and 3D visualization; foraminifera; cuttings 


\section{INTRODUCTION}

Identification of foraminifera is based on the identification of external as well as internal morphological characteristics. Since Schmidt (1952) and Hay and Sandberg (1967) used an X-ray device and scanning electron microscope (SEM) in micropalaeontological study for the first time, no new methods or technological innovations for observation and illustration of microfossils have been introduced. The scanning electron microscope images provide information only about the external morphology. With an SEM device, further study of the specimens is limited due to the sample preparation, normally due to the gluing on and coating with $\mathrm{Au} / \mathrm{C}$. It is also very difficult to get an acceptable quality of the SEM. For the observation of internal morphological features, the conventional method used is the transmitted light microscopic investigation of thin sections of rocks or isolated specimens. There are several disadvantages of this method: it destroys the sample, is time consuming, and demands extensive technical and professional skills.

Study of the internal structure is essential in several micropalaeontological studies:

1. when the extraction of the microfossils from the rock is impossible,

2. for the systematic classification of some groups, e.g., larger foraminifera, radiolaria (entactinarians), Dasycladacea and Rhodophycea, and

3. for ontogenetical studies e.g., the size of the proloculus and the shape of the arrangement of the juvenile chambers of the planktonic and larger foraminifera.

To circumvent the limits of existing techniques, we tested a new method, which is nondestructive and simultaneously allows the study of internal and external morphologies of foraminifera. Theoretically, an appropriate method for these purposes is the Computer Tomograph, which is used worldwide in medical applications. As a result of the technological advances of this device, the micro-Computer Tomograph (micro-CT) was developed at the end of the 1980s. During a micro-CT measurement - similarly to the conventional CT the sample is irradiated with X-rays, which can provide section images in any spatial direction. From these images it is possible to create $3 \mathrm{D}$ models having $1-10 \mu \mathrm{m}$ spatial resolution, which is the most suitable for the study of microfossils.

The micro-CT has been successfully used in petrography and in some cases in vertebrate pal- aeontology (e.g., Mees et al., 2003; Rossi et al., 2004; Burrow et al., 2005; Claessens et al., 2009). In fact, the micro-CT can prove its applicability in invertebrate palaeontology, as well as ichnology. It was tested, for example, on brachiopods, echinoderms (Stock et al., 2003a, 2003b), ammonites, insects (e.g., Dierick et al., 2007; Heethoff et al., 2009; Penney et al., 2007; Pakhnevich and Bryantseva, 2007), mollusc shells (Monnet et al., 2009) and microborings (e.g., Tapanila, 2008; Schönberg and Shields, 2008). There are only a few short papers on surface and volumetric quantifications of several foraminifera specimens (e.g., Speijer et al., 2008; Briguglio, 2010). Following our research since 2007 (Szinger et al., 2007), the aim of this work is to develop a general methodology for the use of the micro-CT in foraminifera taxonomy as well as in applied micropalaeontology (e.g., core and cuttings) reflecting both the advantages and the limits.

\section{MATERIAL AND METHODS}

In our study isolated specimens of foraminifera, rock fragments, washing residues of the rock, cuttings with mud, washed cuttings and resin-fixed cuttings were measured. Foraminifera are a suitable group for testing the micro-computed tomography. Their average size $(50-300 \mu \mathrm{m})$, diversity of their external morphology (chamber shape and arrangement), of the internal structure (e.g., septa, beams, rafters, canal and cavity systems), of the material (calcite, aragonite or arenaceous) and of the texture (e.g., perforated, non-perforated, agglutinated, one or more layered) of their skeleton made them promising subjects for these preliminary studies. The specimens originated from different ages and have different states of preservation (empty or filled with matrix of the rock; with original wall texture or with a recrystallised one).

The studies were performed on a SkyScan1172 system, which is a high-resolution desktop Xray microfocus computerized tomography system, and consists of an X-ray microfocus tube (20$100 \mathrm{kV}, 10 \mathrm{~W},<5 \mu \mathrm{m}$ spot size, target material of the tube: tungsten), a rotating specimen stage and a two-dimensional X-ray detector. The detector comprises a scintillator screen (gadolinium oxysulphide phosphor, dimension: $25 \times 25 \mathrm{~mm}$ surface and 25 $\mu \mathrm{m}$ thickness), fibre optics and a CCD sensor (1.3 Mp cooled CCD, 12 bit gray levels). The maximum object size is $20 \mathrm{~mm}$ in diameter for a standard scan, and the low-contrast resolution is $5 \mu \mathrm{m}$.

The micro-focus $X$-ray source illuminates the sample, and the X-rays interact with the matter and 


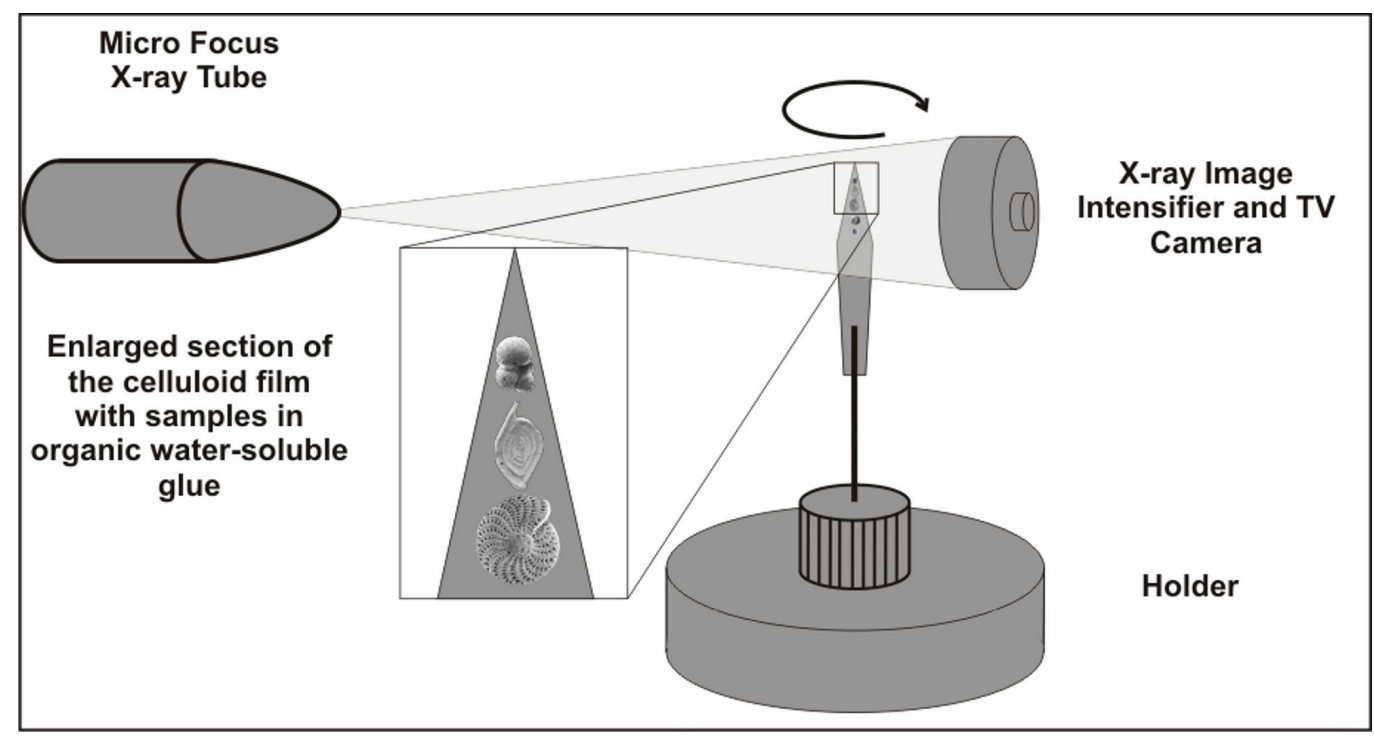

FIGURE 1. Sketch of the measurement techniques in micro-CT device.

attenuate. This attenuation is dependent on the density and atomic number of the object radiated and on the X-ray energies used (Figure 1). The planer X-ray detector collects the magnified projection images. Hundreds of angular shadow images are acquired while the object rotates, thereafter, a computer program synthesizes these images into virtual slices through the X-ray absorbent object. The reconstruction program uses a modified Feldkamp algorithm allowing the simultaneous collection of data throughout the full 3D volume of small specimens. The reconstruction includes alignment optimization, beam-hardening and ring artifact corrections. A detailed description of the basic principle of micro-CT, data acquisition and image reconstruction can be found in the literature (e.g., SkyScan 2005).

The numerical and visual rendering of the acquired datasets were performed and tested in steps by using different commercially available software (TView, NRecon, DataViewer, DICOM-CT, CTAn-CTVol, Osiris4, MVE, MicroView, Amira) (Figure 2).

During the rendering, the setting of the filtering (e.g., density thresholds, ROI, gray scale) was adjusted to obtain the best images.

As a result of software rendering, $2 D$ and $3 D$ images, moreover 3D animations of foraminifera can be generated, or cross-sections can be cut in any directions.

\section{RESULTS OF WORKFLOW OPTIMIZATION}

\section{Preparation and Measurement Techniques}

During the measuring process, the rock fragments were fixed in a conventional way using X-ray transparent plasticine.

However, the majority of the micropalaeontological samples are small-sized (up to $300 \mu \mathrm{m}$ ) or consist of small pieces like washings residue and cuttings. We did not find any published method as to how to place such samples in a suitable position in the rotation-axis of the micro-CT holder, to fix them stably for hours of measurements and to remove them without destruction. Another practical question was how to measure the largest volume at the best (or the most suitable) resolution during the shortest time with the simplest preparation for the isolated specimens, for the rock sample or for the cuttings.

Based on our experiments, a strip (about $0.5 \mathrm{x}$ $2.5 \mathrm{~cm}$ ) of X-ray celluloid film was found as the most suitable for holding the isolated microfossils and an organic water-soluble glue (gomme adragante applied by wet ultrathin paintbrush) for fixing them. Depending on the required resolution and the size of the samples, three to four specimens can simultaneously be measured. Since the microCT device is suitable for serial measurements, by applying the same settings of the measuring parameters, up to 10 to 12 specimens can be fixed on the celluloid film and scanned without any human intervention (Figure 3). Using this preparation technique one isolated specimen requires only about half an hour of measuring time. 


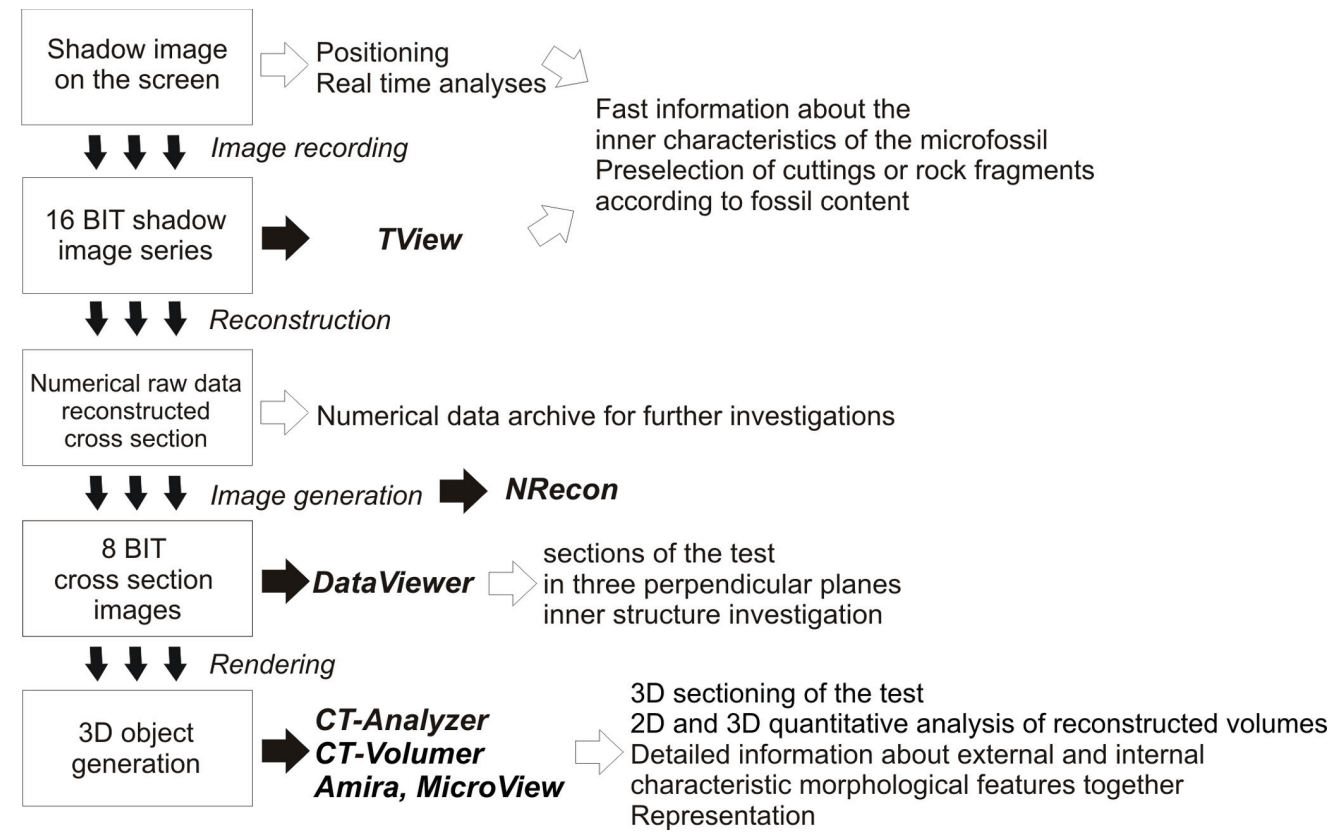

FIGURE 2. Workflow diagram of acquisition and numerical and visual rendering with proposed software packages (modified after SkyScan 2005).

For the study of larger amounts of material, like rock fragments and cuttings, a volume of 1-2 $\mathrm{cm}^{3}$ with a cylindrical shape is ideal. To hold the cuttings and to minimize the X-ray attenuation, a thin-walled plastic tube (approximately about $d=5$ $\mathrm{mm}$ and $\mathrm{h}=30 \mathrm{~mm}$ ) closed with plasticine is found to be the best solution. At the measuring of cuttings, the drilling mud has no disturbing influence on the quality of the shadow image, although it decreases the substantial volume. To avoid the movement of smaller fragments during the rotation of the holder, the cuttings were strongly compacted. A two-component resin was used for fixing, too, but the glue required about 12 hours to bond. Depending on the volume, type of sample and the mode of investigation, the time-span of a measurement is $1-15$ hours, the average being 4 hours.

\section{Visualization}

The high-resolution X-ray shadow image can be seen on the monitor of the micro-CT device, which turns around with the adjusted angles in real time, and this series of images can be captured and saved in TIFF format. The screen images are suitable for fast analyses of isolated foraminifera as well as rock fragments or cuttings. The resolution depends on the volume, but for the isolated microfossils, we could get high-quality images. The chamber arrangement, which is essential for the identification of foraminifers in several cases, (e.g., arenaceous forms), is invisible when using a tradi- tional light or a scanning electron microscope. This feature, however, can easily be studied with micro$\mathrm{CT}$, especially when a convenient orientation is used (Figure 4). Due to the easily removable gluing, the observation of the same specimen in different views is also possible.

Another advantage of the method is the ability for the preliminary investigation of small quantities $\left(\sim 1-2 \mathrm{~cm}^{3}\right)$ of rock fragments or of cuttings without any preparation. Due to the ability to measure very quickly, these preliminary results can help to decide the further treatment or investigation of the material. Information can easily be acquired on quantity and quality of the microfossil, along with the dimensions, volume and shape of the grains, referring also the sedimentological features. However, in these cases the spatial resolution is not good enough for the exact identification. With the help of washing the valuable sample volume can be increased. This way, micro-CT is an ideal tool for preselection (Figure 5).

Opportunities for the volumetric rendering using micro-CT are illustrated with case studies on isolated microfossils and cuttings.

First, we chose a group of foraminifera, the miliolids (studied genera are Triloculina and Spiroloculina) where both the external and internal characteristics are required for the identification of species, and even the genera. Traditionally, these characteristics could be observed with two different processes: using a light microscope on isolated 


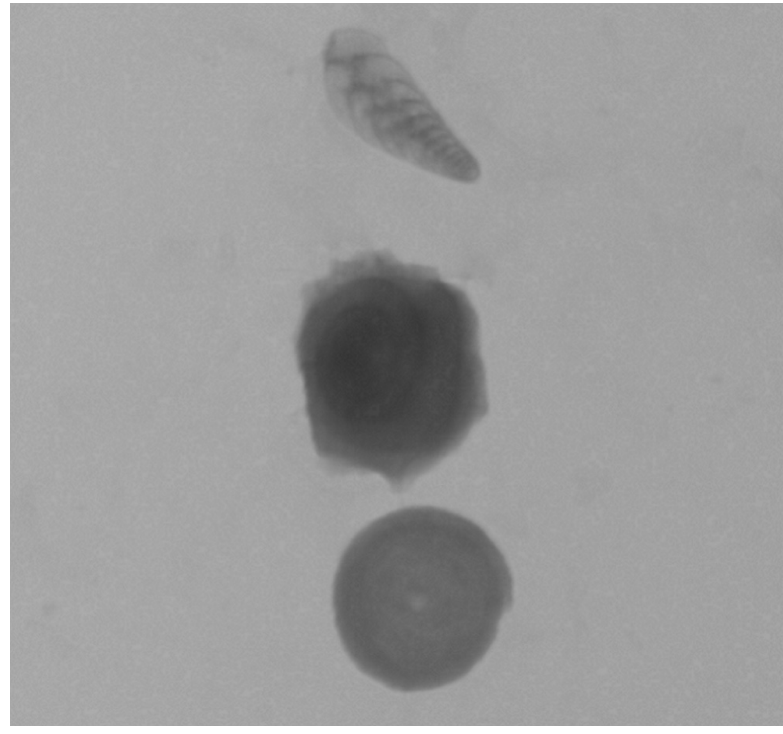

FIGURE 3. Specimens with different wall material fixed with gomme adragante (water-soluble glue) on celluloid films. Bottom to top: Spirillina infima (Strickland, 1846) (Jurassic, Som Hill, Transdanubian Range, Hungary), Paalzowella scalariformis Paalzow, 1917 (Jurassic, Som Hill, Transdanubian Range, Hungary), Bolivina dilatata Reuss, 1850 (Badenian, North Hungarian Range). The largest diameter is $300 \mu \mathrm{m}$.

specimens on the one hand and on oriented thin sections on the other. The latter preparation technique is delicate, time consuming and destructive for the sample.

Miliolids have an imperforate calcite wall and their main diagnostic characteristics on the generic level are the chamber arrangement and the shape and restricted (or auxiliary) elements (e.g., tooth) of the aperture (Łuczkowska, 1972; 1974; Loeblich and Tappan, 1988). There are two diagnostic sections of the miliolids, one which penetrates the embryonic chamber (it is in the innermost part of the test) in the coiling axis, across the aperture and the other is perpendicular to it (Figures 6, 7, 8, 9, $10,11,12,13,14,15,16,17$, and 18).

The micro-CT provides an easy option to fix the coiling axis and adds the position of the virtual section, thus the characteristic sections can easily be produced. For example, in Figure 8 applying angle metering or any graphic program it is easy to measure that by each chamber on the last whorl the coiling plane rotates by $120^{\circ}$, which is the triloculine chamber arrangement. It is possible to make the last, outermost chambers translucent. In this way, the inner chambers, and hence the early quinqueloculine stage, can be observed (Figure 7). Another diagnostic characteristic, the tooth, can

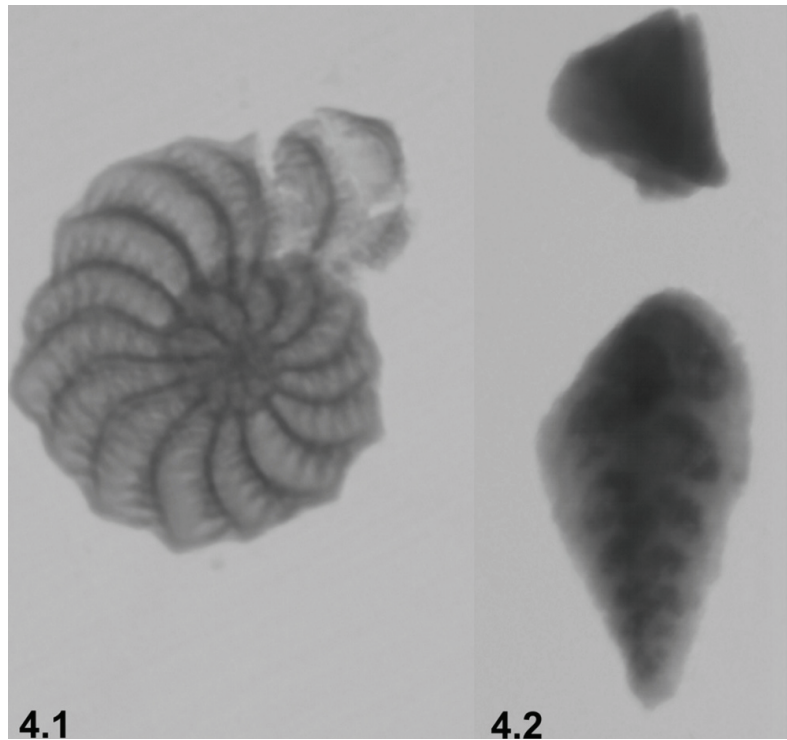

FIGURE 4. X-ray shadow images of (4.1) hyaline Elphidium macellum (von Fichtel and Moll, 1798) (Sarmatian, Zsámbék Basin, North Hungary) (the largest diameter is $400 \mu \mathrm{m}$ ) and (4.2) agglutinated Tritaxia tricarinata (Reuss, 1844) (Cretaceous, Magyarpolány, Transdanubian Range) test (the largest diameter is 250 $\mu \mathrm{m})$ of foraminifera.

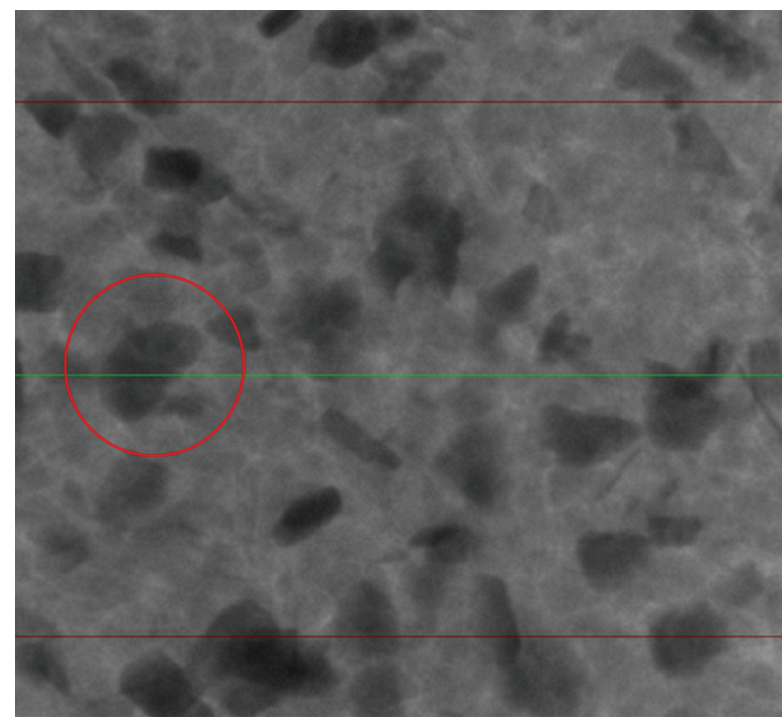

FIGURE 5. X-ray shadow image of the Badenian (Székkutas, SE-Hungary) cuttings in plastic tube holder. Red circles indicate the foraminifera. The largest diameter of the foraminifera is $300 \mu \mathrm{m}$.

also be studied by using the 3D rendering programs (Figures 9,12). Measuring the size or the volume of the proloculus and the first chambers can give information about the ontogeny or distinguish the microsphaeric and macrosphaeric generations. 


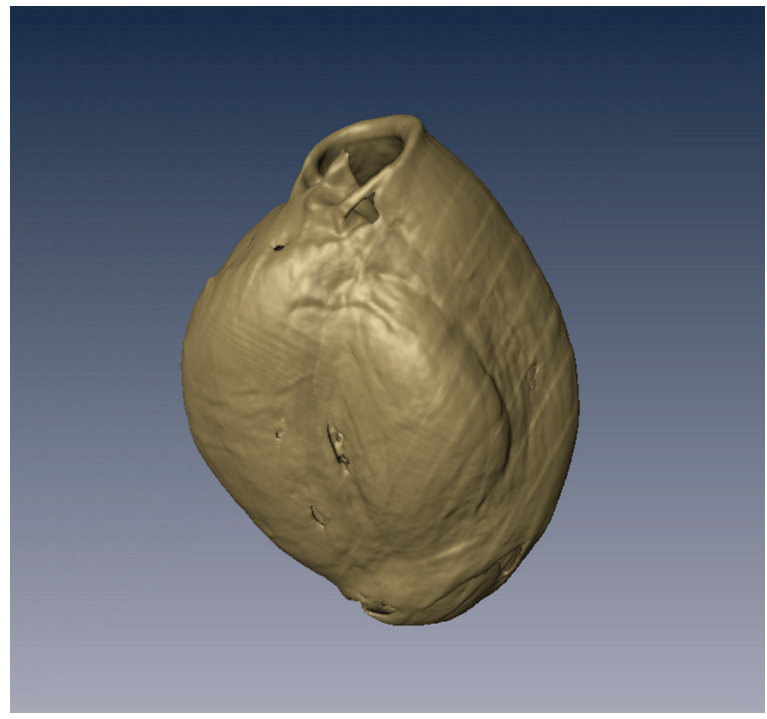

FIGURE 6. 3D model of Triloculina schreiberiana d'Orbigny, 1839 (Recent, Zadar, Adriatic Sea), side view (Amira software). The largest diameter is $350 \mu \mathrm{m}$.

In the case of planktonic foraminifers (studied specimens are Globigerina sp.), the small size and the fragility of the skeleton make it very difficult to produce thin sections from isolated specimens. This problem could also be solved by using microCT (Figures 19, 20).

The sectioning is especially important in some unique planktonic forms like orbulinids (Figures 21, 22) having the last large, spherical chamber, which covers all the former diagnostic ones. It is a timeconsuming and very delicate task to remove

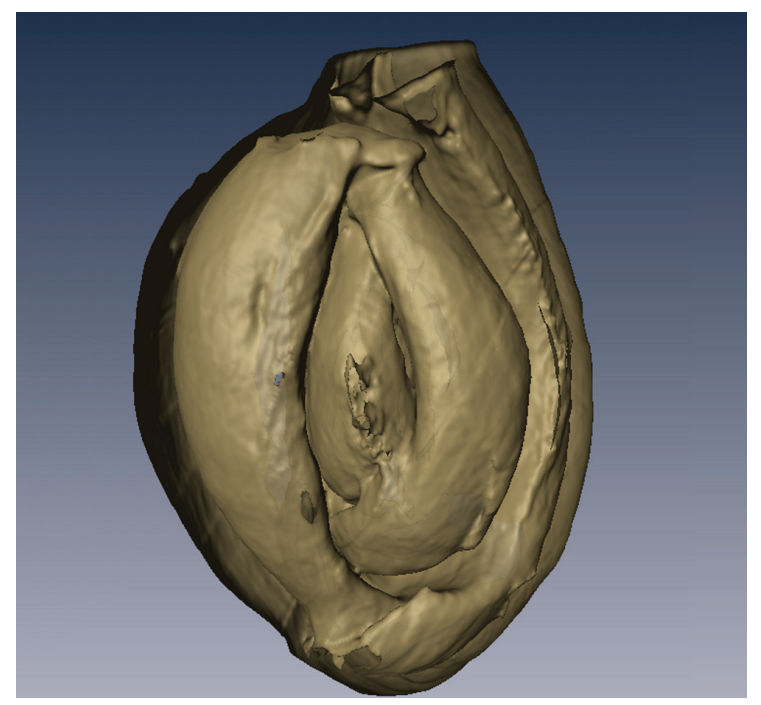

FIGURE 7. 3D model of Triloculina schreiberiana d'Orbigny, 1839 figured on Figure 6, with translucent last chambers, side view. (Amira software). The largest diameter is $350 \mu \mathrm{m}$.

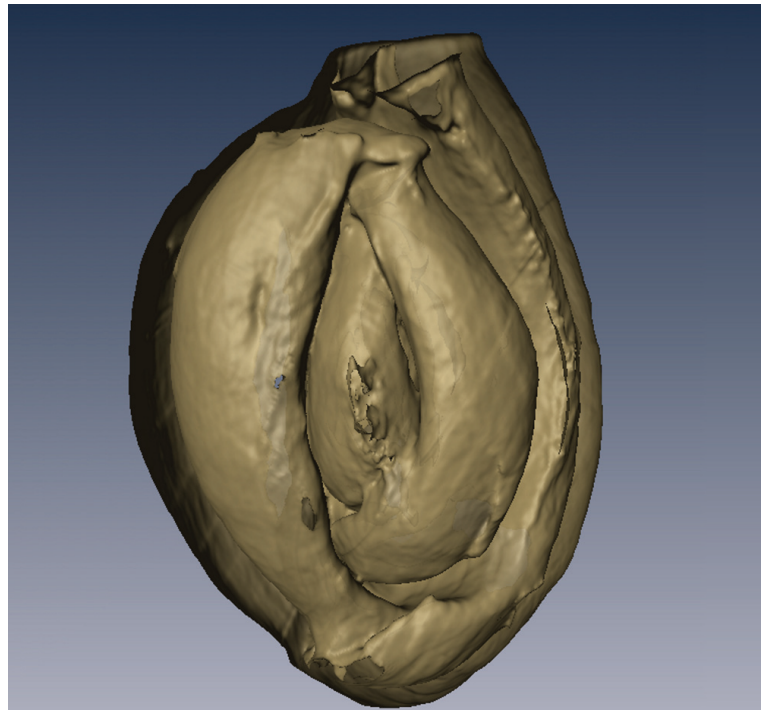

FIGURE 8. Section across the embryonic chamber of the 3D models of Triloculina schreiberiana d'Orbigny, 1839 illustrated on Figure 6 (Amira software). The largest diameter is $350 \mu \mathrm{m}$.

mechanically the wall of the last chamber under microscope. This work can be avoided applying micro-CT.

For the taxonomical study of trochospiral foraminifera, three views (spiral, umbilical and side) are necessary. Due to the small-sized planktonic foraminifers, the diagnostic characteristics (e.g., the orientation of the coiling axis, the position and the shape of the aperture, and the surface ornamentation) are usually difficult to observe under the

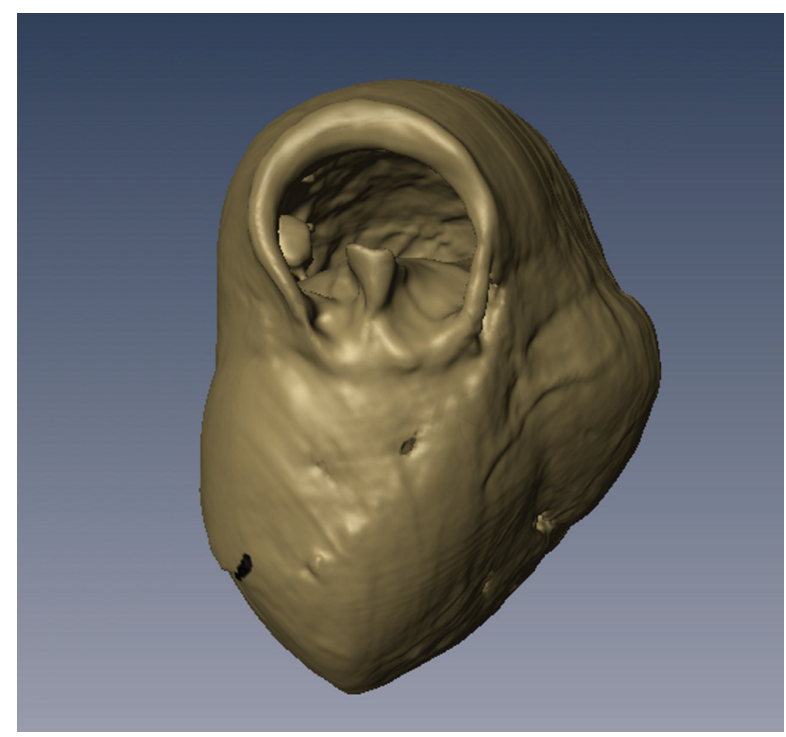

FIGURE 9. 3D model of of Triloculina schreiberiana d'Orbigny, 1839 illustrated on Figure 6, apertural view (Amira software). The largest diameter is $350 \mu \mathrm{m}$. 


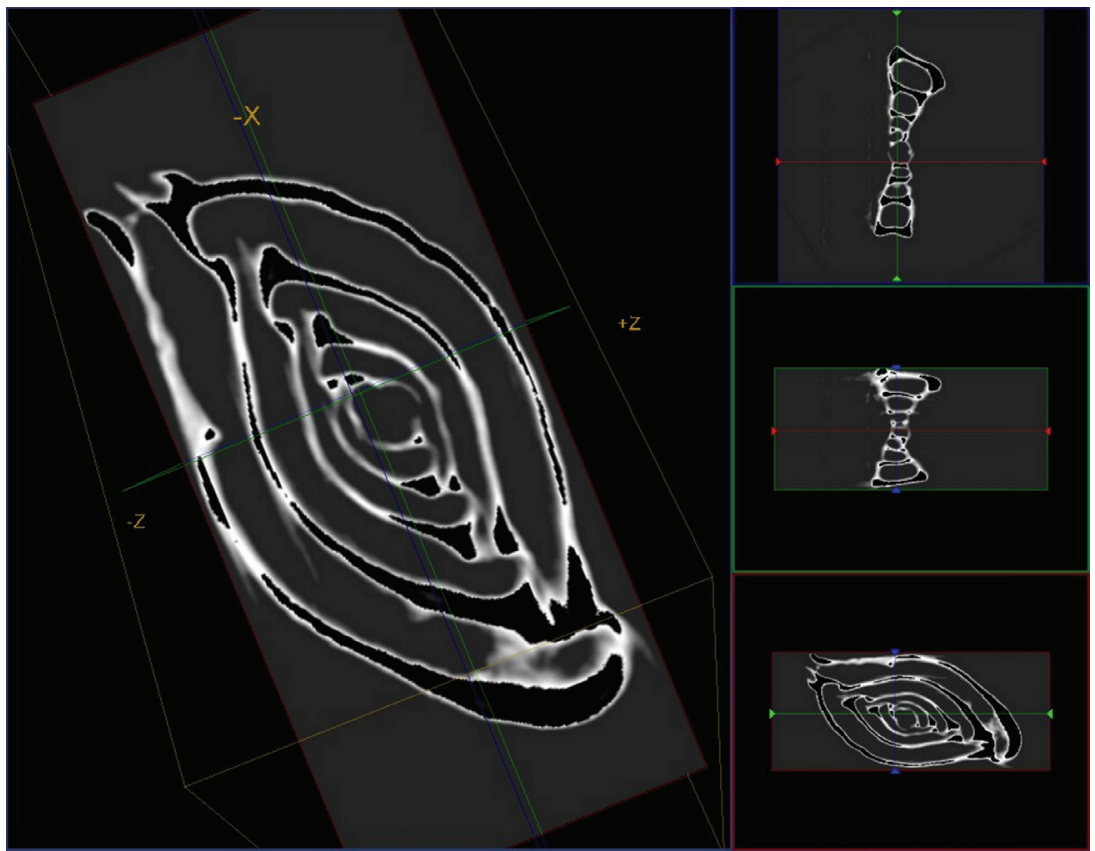

FIGURE 10. Apertural section penetrating the embryonic chamber (large image) of Spiroloculina cymbium d'Orbigny, 1839 (Recent, Zadar, Adriatic Sea) and three perpendicular views (right side) (MicroView software). The largest diameter is $350 \mu \mathrm{m}$.

light microscope. It is also problematic to fix the small-sized $(50-150 \mu)$ benthic specimens in the suitable position for the SEM pictures. Even if successful, it is also questionable whether the three specimens, from which the three views are obtained, belong to the same species. With the

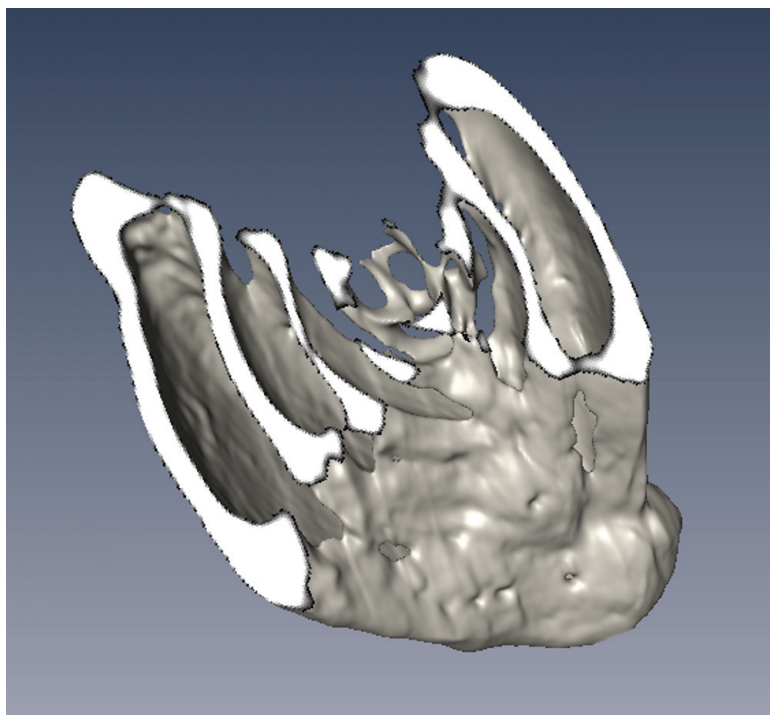

FIGURE 11. Section across the embryonic chamber of the 3D models of Spiroloculina cymbium d'Orbigny, 1839 figured on Figure 10 (Amira software). The largest diameter is $350 \mu \mathrm{m}$. help of volumetric rendering, these characteristic views of the same specimen can be better studied.

In the investigation of cuttings, washing residues and rock fragments, the visualisation technique allows the making of virtual sections in any direction, similarly to the isolated forms as discussed above. These sections provide useful infor-

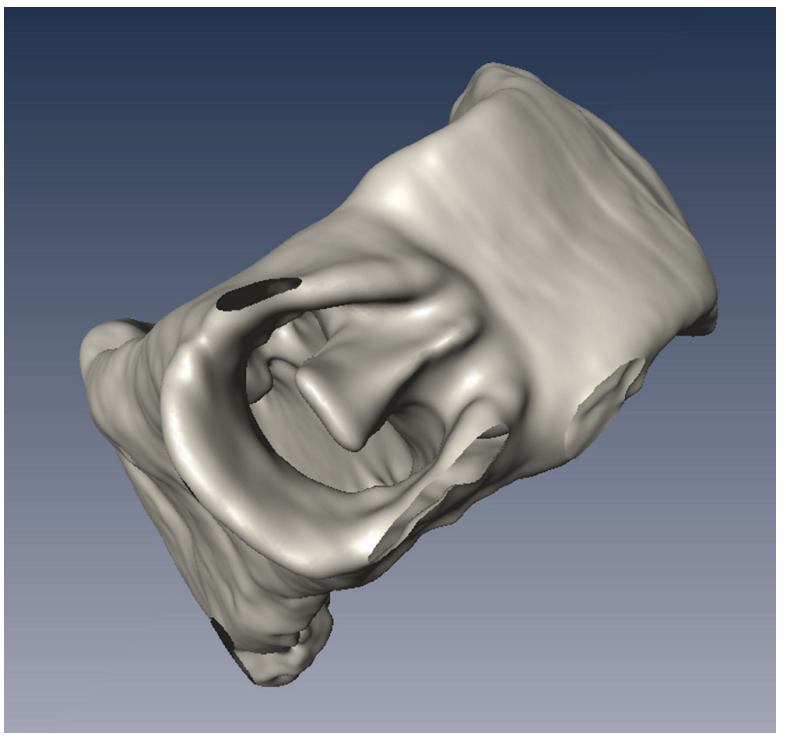

FIGURE 12. 3D model of of Spiroloculina cymbium d'Orbigny, 1839 illustrated on Figure 10, apertural view (Amira software). The largest diameter is $350 \mu \mathrm{m}$. 


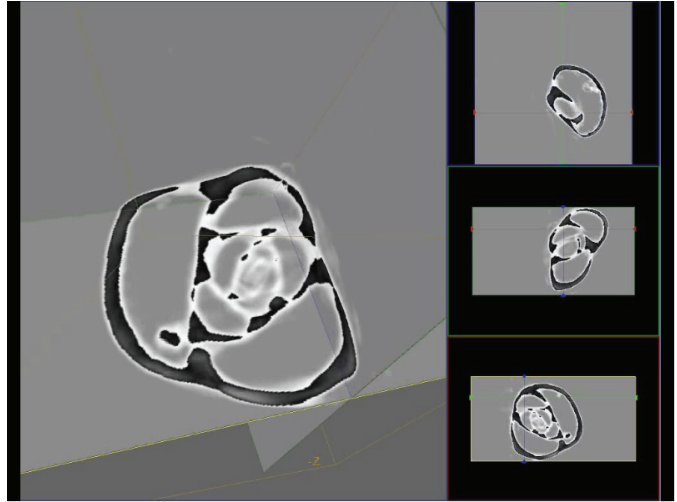

FIGURE 13. Sectioning in three perpendicular planes of Triloculina schreiberiana d'Orbigny, 1839 illustrated on Figue 6 (MicroView software).

PE note: all animations are available online at palaeoelectronica.org

mation about the bio- and lithoclasts composition of the studied material, as demonstrated in the washing residue of selected Carpathian (Lower Miocene) and Sarmatian (Middle Miocene) beds (Figures 23, 24).

\section{DISCUSSION}

Based on our research, we could not find any technical drawbacks for the application of the micro-CT in micropalaeontology. Its advantages

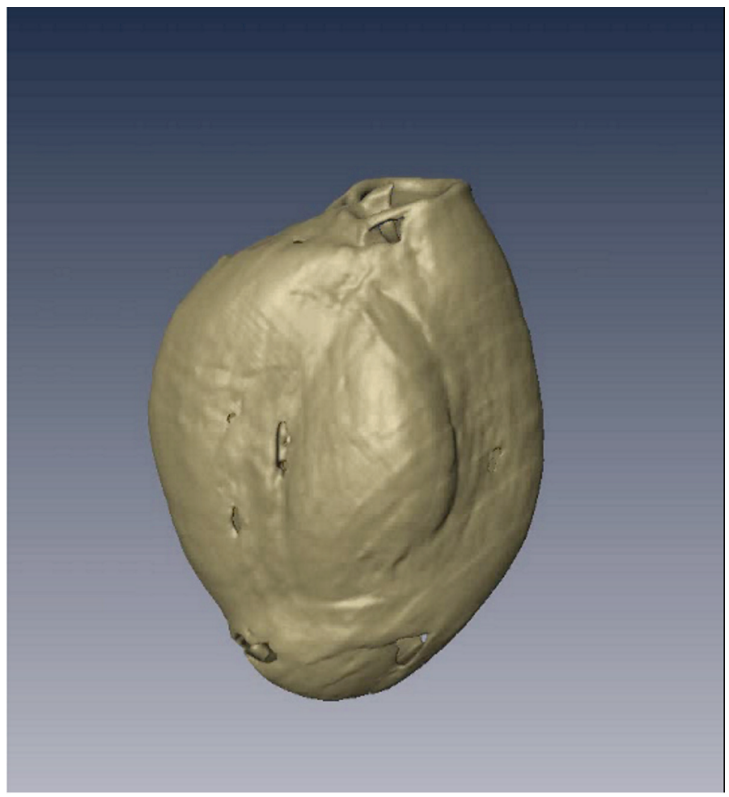

FIGURE 14. Animation of the 3D model of Triloculina schreiberiana d'Orbigny, 1839 illustrated on Figure 6 (Amira software).

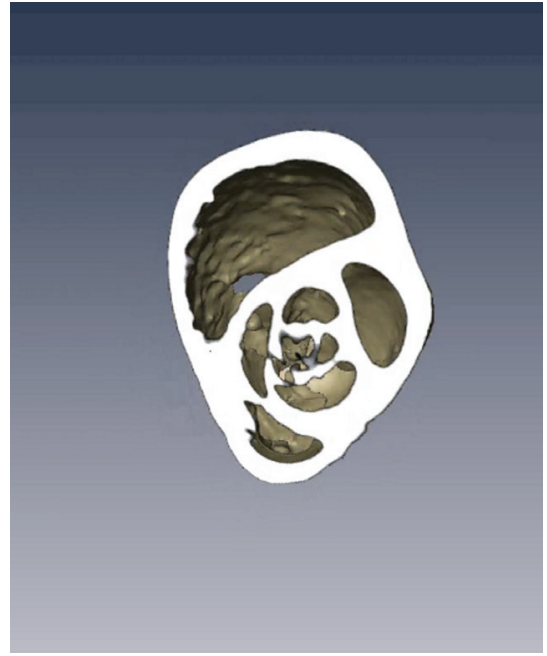

FIGURE 15. Arbitrary sectioning of the 3D model of Triloculina schreiberiana d'Orbigny, 1839 illustrated on Figure 6 (Amira software).

and limitations are summarized in the following paragraphs.

\section{Advantages}

The sample preparation proposed in this study is fast, cheap, non-destructive and re-usable for further investigation.

One of the main advantages of this visualization technique in the classical micropalaeontological studies is to save the valuable and

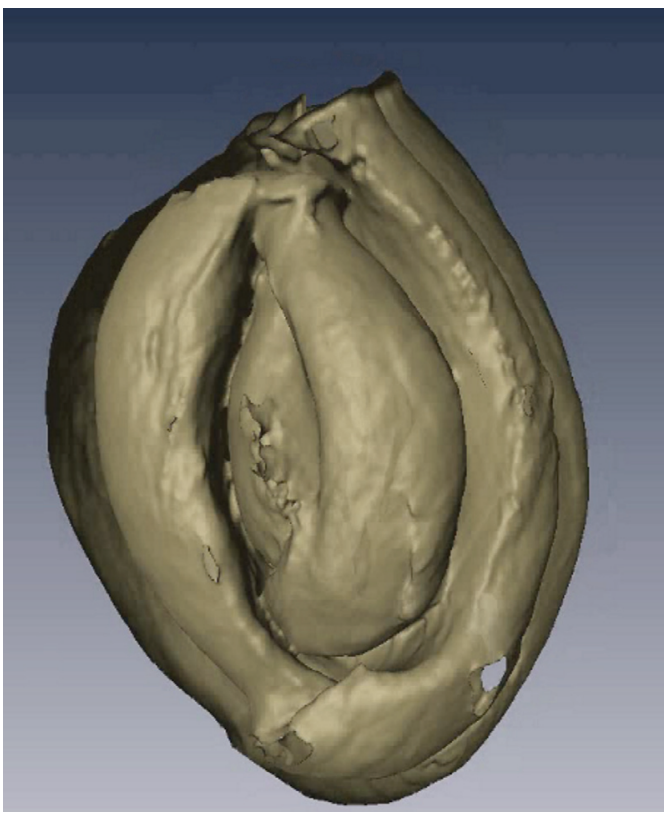

FIGURE 16. 3D animation of Triloculina schreiberiana d'Orbigny, 1839 illustrated on Figure 6, with translucent last chambers (Amira software). 


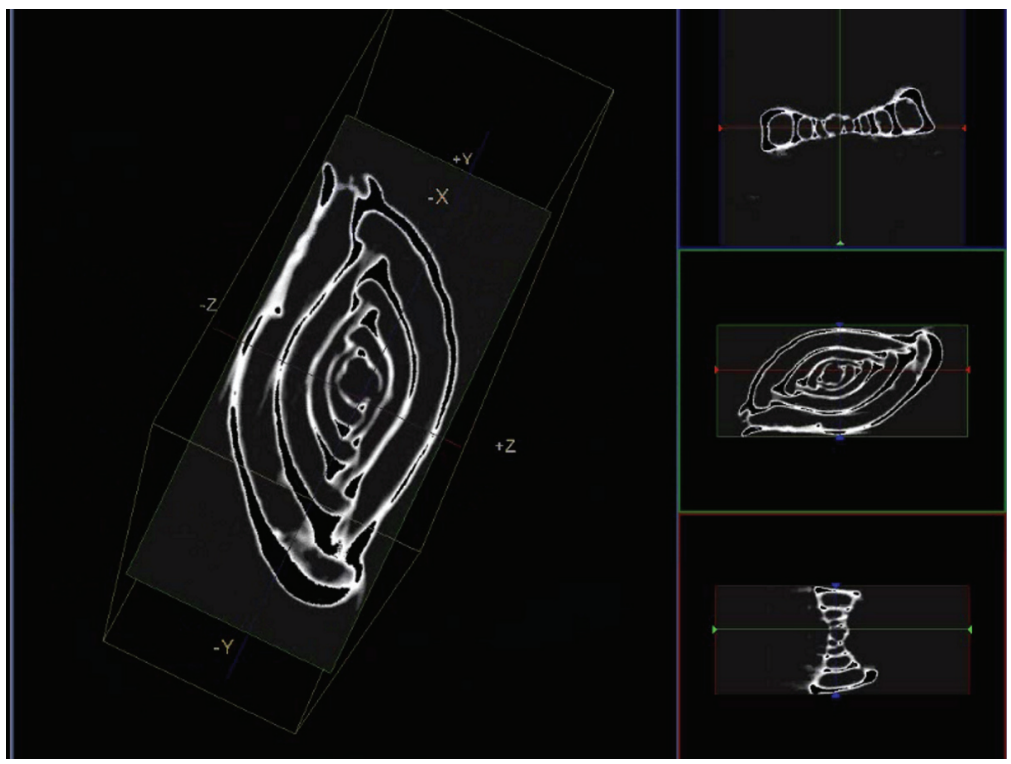

FIGURE 17. Sectioning of Spiroloculina cymbium d'Orbigny, 1839 illustrated on Figure 10 and three perpendicular views (right side) (MicroView software).

irreplaceable specimens from destruction during preparation or measurement. Thus, it is possible to study the structural details of precious type specimens/holotypes.

According to the aim of the foraminifera investigation (e.g., content, amount, identification, description, illustration) the process can be stopped at the required point of the workflow (Figure 2). Dimensions and volume calculations are the basic function of all programs which we used.

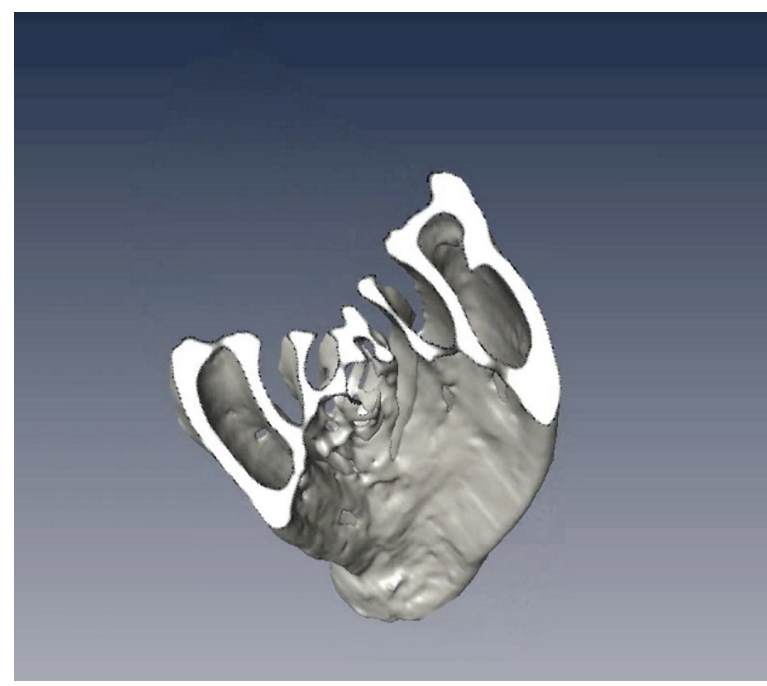

FIGURE 18. 3D animation of Spiroloculina cymbium d'Orbigny, 1839 illustrated on Figure 10, with translucent last chambers (Amira software).
In real time the investigation of the samples (position, identification of Region of Interest (ROI), along with the quality of the final results) can be checked, the first analyses of the microfossils can be done on the monitor of the device.

In a short time, high-resolution 2D X-ray shadow images could give important information about the inner structure of the microfossils and the sedimentological characteristics of the rocks and cuttings due to the short and easy preparation procedures and the high speed of measurement.

Even the less advanced software packages make it possible to cut the investigated specimen in three perpendicular planes at the beginning of the workflow. Since both the cutting points and planes can be optionally positioned, it is easy to get any desired section of the foraminifera.

An advanced way to present the characteristic morphological features is the $3 \mathrm{D}$ reconstruction. Free movement, rotation, zooming, cutting-off or sectioning of the models of the specimens can be performed on the rendered object. This method obviously makes it possible to receive more detailed information on both the external and internal characteristics of the test. It can facilitate the taxonomical studies (identification and classification of the taxa) of some microfossil groups because it is possible to make $3 D$ rendering and sectional images of the skeleton in any direction with the help of different software. By obtaining these spatial slices, the external and internal morphological features could be observed together. In 


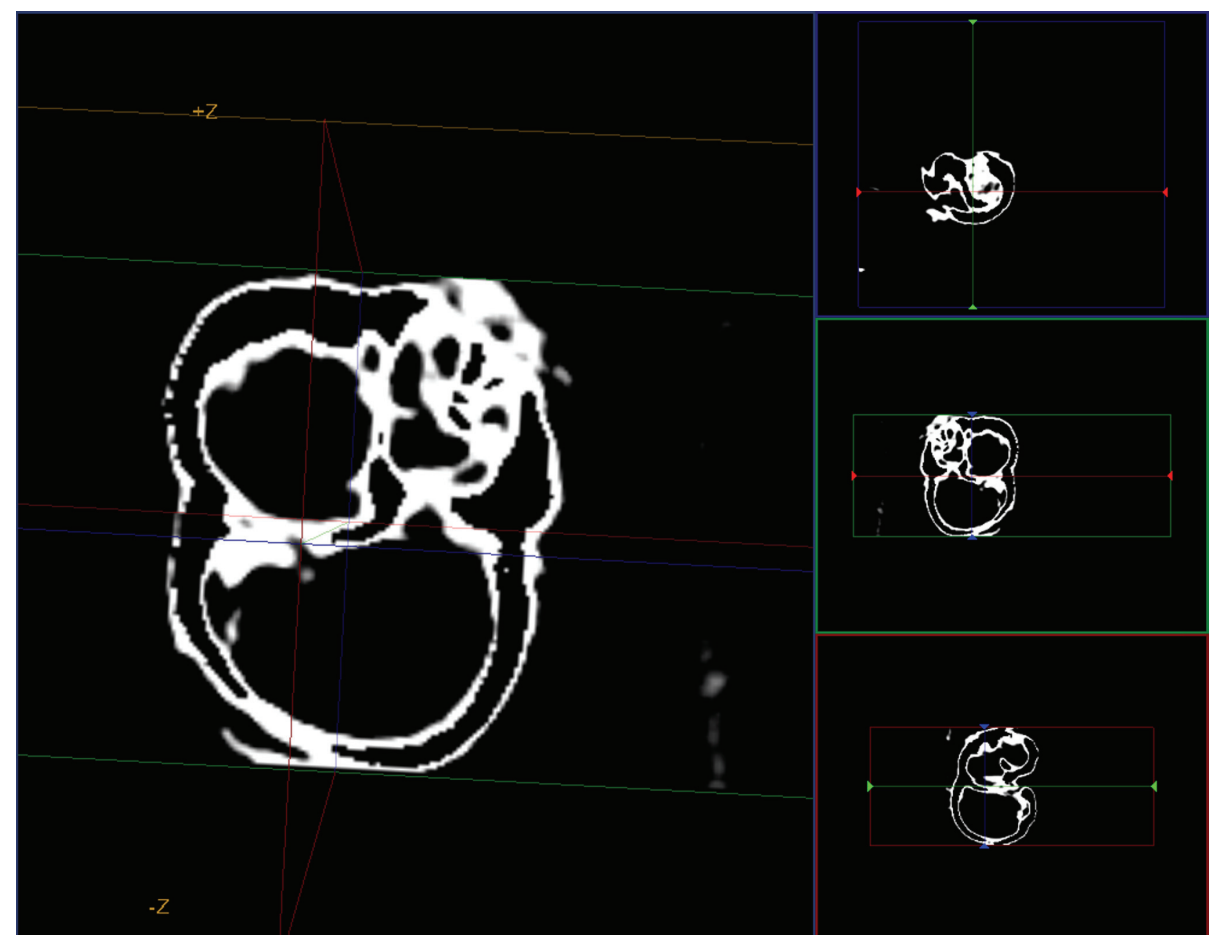

FIGURE 19. Axial section of Globigerinoides trilobus (Reuss, 1850) (Badenian, North Hungarian Range) and three perpendicular views (right side) (MicroView software). The largest diameter is $200 \mu \mathrm{m}$.

addition, as a proof for the high quality of these rendered 3D models, it is possible to measure any quantitative parameters of the skeleton with high precision. Moreover, this method allows the 3D reconstruction of the species described only from thin sections and unknown as isolated form. Vice versa, to help the identification from thin sections, a rendered microfossil section atlas would be suitable for both scientific and educational purposes. The technique facilitates the ontogenetic studies and thus it helps in the investigation of phylogenetic relationships.

In applied micropalaeontology, the X-ray images of the cuttings permit the fast pre-selection

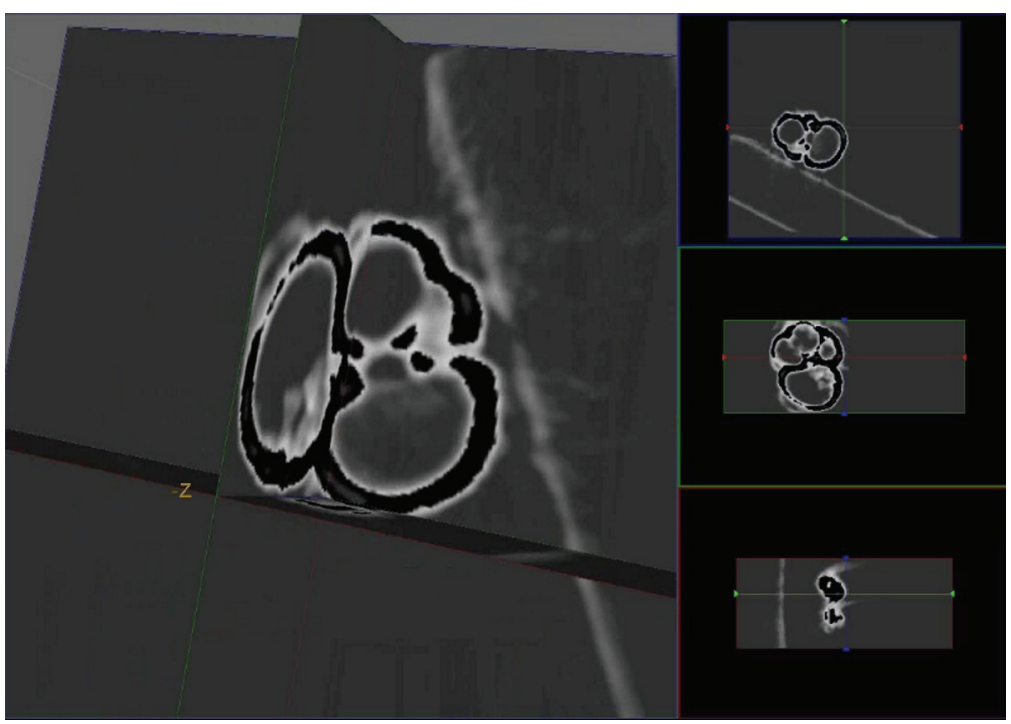

FIGURE 20. Sectioning of Globigerinoides trilobus (Reuss, 1850) illustrated on Figure 19 and three perpendicular views (right side) (MicroView software). 


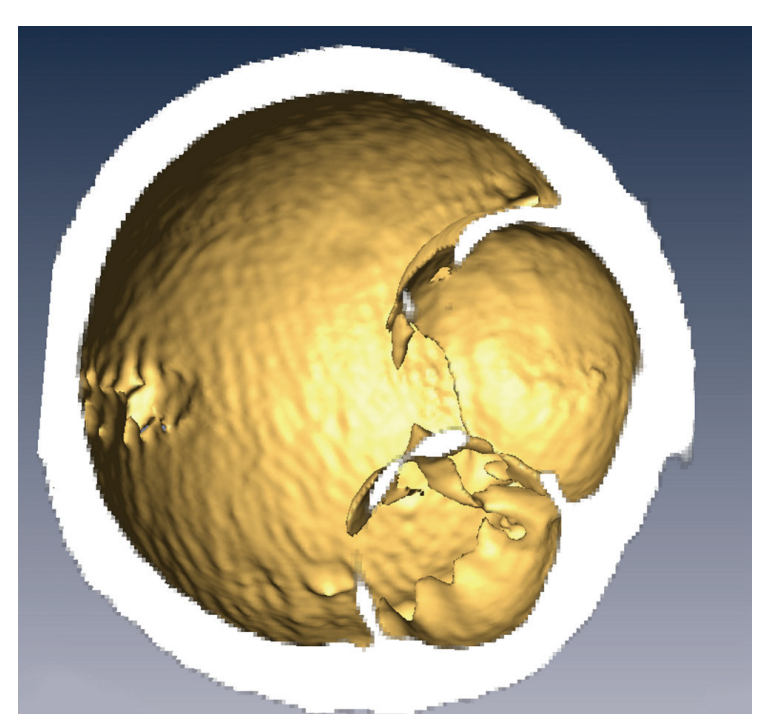

FIGURE 21. Section across the juvenile chambers of the 3D models of Orbulina universa d'Orbigny, 1839 (Badenian, North Hungarian Range) (Amira software). The largest diameter is $150 \mu \mathrm{m}$.

of the faunal bearing samples for further investigation. A portable micro-CT device would be suitable for the continuous observation of the cuttings during well drilling. The results of the measurements can be stored in digital format, which are easy to handle with computers and can be sent over the Internet to a specialist anywhere in the world.

The measured numerical data can be processed using different software packages to get the best results or they can be re-processed as new software appears on the market. It is possible to transform the data into different formats (images, movies) for publication or presentation.

\section{Limitations}

Since the image construction is based on the scanning of areas with different average density and atomic number ( $Z$ ), if the carbonate skeleton is recrystallised and filled with sparrycalcite, it is not suited to micro-CT investigation (Figure 25).

Depending on the resolution, it is difficult to measure very small-sized $(<50 \mu \mathrm{m})$ foraminifers with some micro-CT devices. In this case, to achieve the required resolution, it is necessary to reduce the distance between the detector and the sample. This modification can cause contact between the detector and the sample holder, such that the rotation of the sample is hindered.

Because of the attenuation of the different frequency X-ray waves, smaller samples yield better resolution. Smaller samples yield better resolution, which is why the measurement of rocks, cuttings or core samples with larger volume can provide only indicative information about the amount of microfossils.

The resolution of the $3 \mathrm{D}$ reconstruction is not enough for the study of the surface ultra-structure.

Historically, the CT devices and visualization software were developed for medical uses and their related specific requirements. Similar development of software or modules (e.g., settings of the filters for the material of different skeletons)

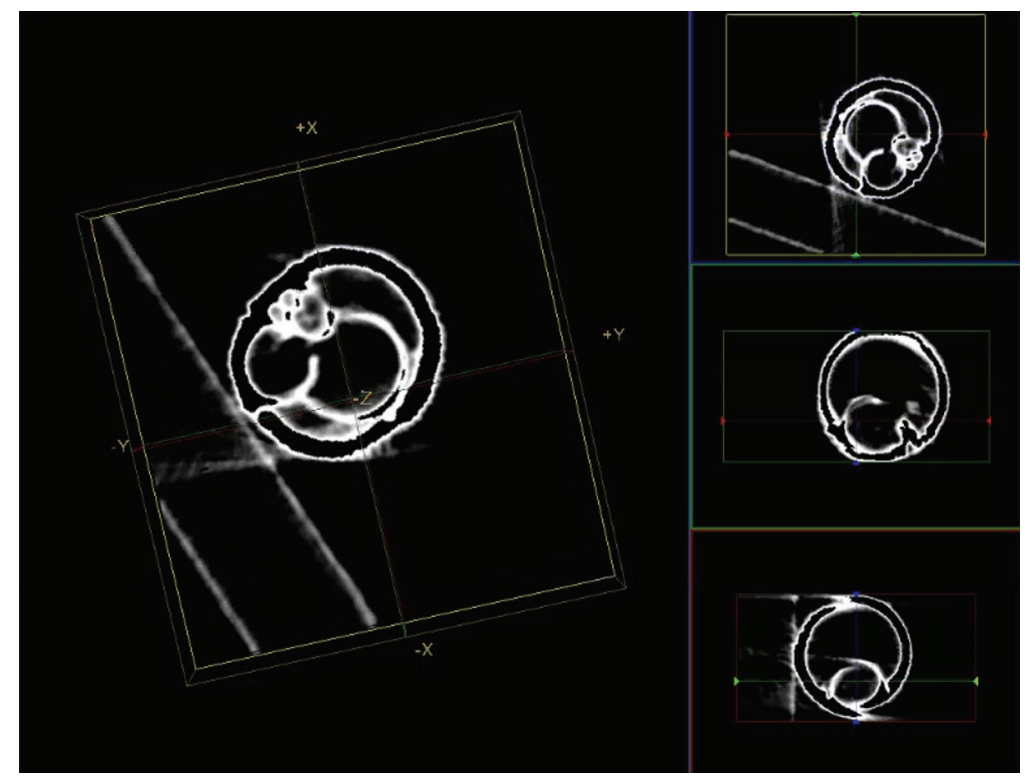

FIGURE 22. Sectioning of Orbulina universa d'Orbigny, 1839 illustrated on Figure 21 and three perpendicular views (right side) (MicroView software). 


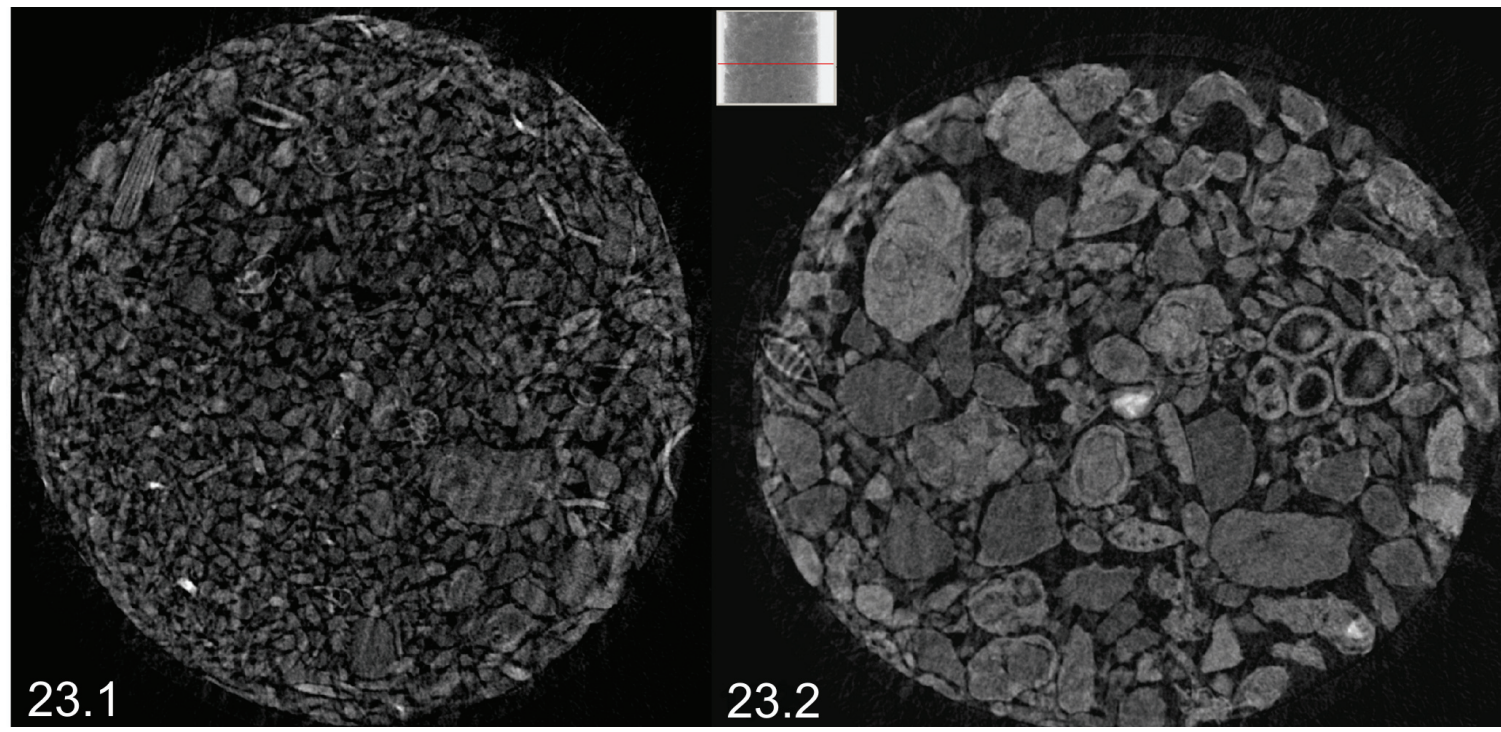

FIGURE 23. Cross section images of Carpathian (North Hungarian Range) (23.1) and Sarmatian (Zsámbék Basin, Hungary) (23.2) washing residue in plastic tube holder (DataViewer software). Diameter of the plastic tube is $3.5 \mathrm{~mm}$.

would be helpful to assist its widespread application in micropalaeontology.

\section{CONCLUSIONS}

Our study demonstrates the usability of microCT in micropalaeontology on isolated foraminifera tests as well as on the microfossil content of smallsized rock fragments and cuttings. First, a method of stable, oriented and removable fixing of the microfossils and cuttings in the device were developed.

A workflow is proposed for foraminiferologists as well as other micropalaeontologists, which can be finished at any step in the procedure when the aim of the study is reached.

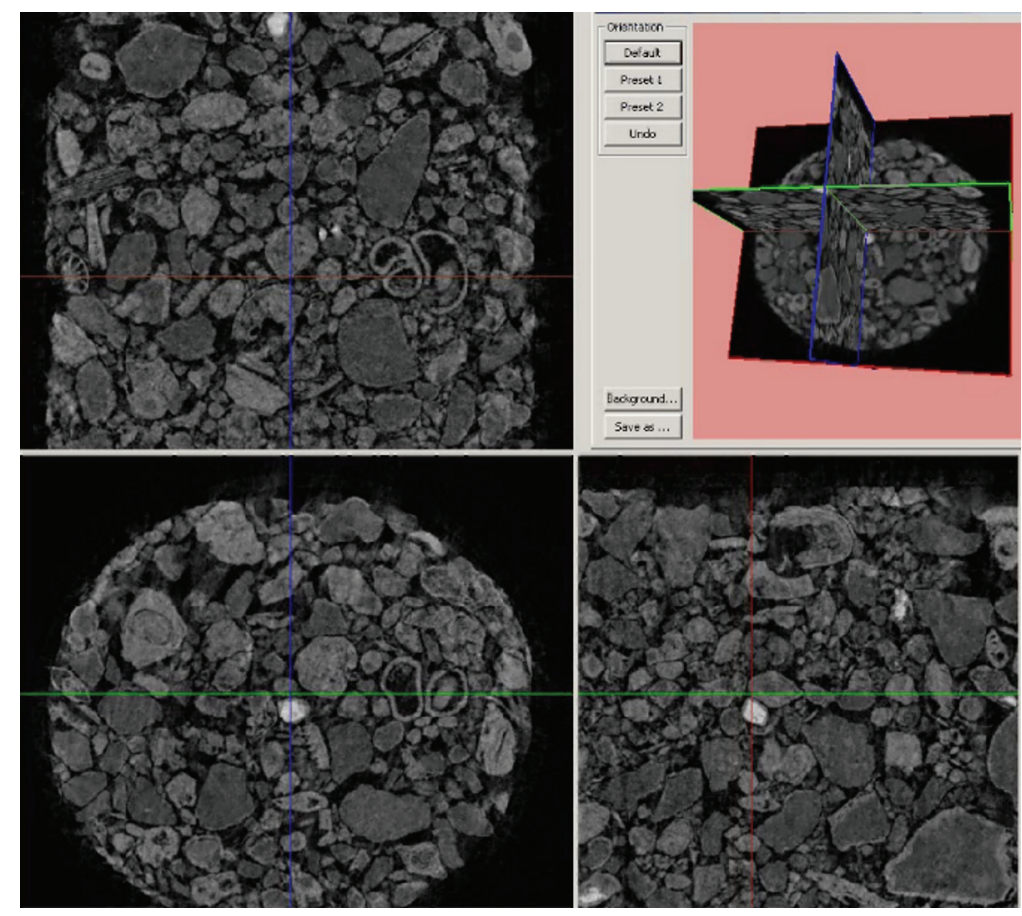

FIGURE 24. Sectioning in three perpendicular views of Sarmatian cuttings (DataViewer software). 


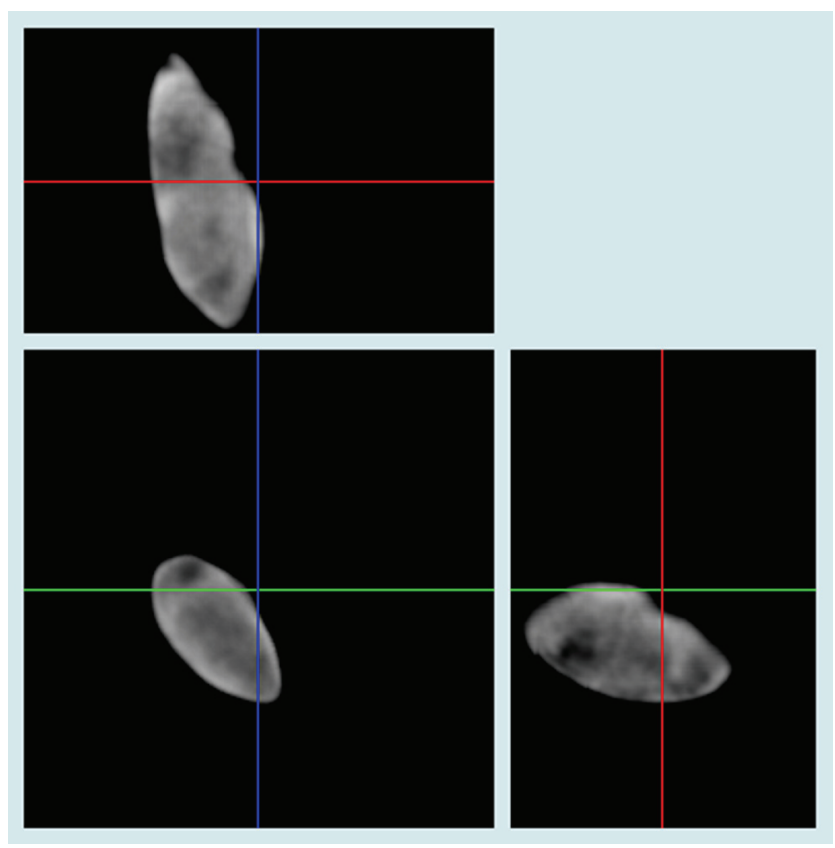

FIGURE 25. Sectioning in three perpendicular planes of recrystallized test and infilled by sparrycalcite of Eoguttulina sp. (Cretaceous, Calvaria Hill, Transdanubian Range) (DataViewer software). The height of the test is $310 \mu \mathrm{m}$.

The high-resolution X-ray image series is well suited to the study of cuttings, and for the preselection of samples for further micropalaeontological investigations. Additionally, these types of images show more deterministic characteristics about foraminifera than those from the light microscope and even those from SEM pictures (e.g., at the specimens with invisible suture because of the smooth or roughly agglutinated surface).

Compared to conventional methods, the volumetric rendering offers opportunities to make any number of arbitrary oriented sections from isolated, as well as, rock-embedded microfossils without destruction. Furthermore, only this method is capable of creating 3D models of the latter kind of sample, also showing the ornamentation of the skeleton surface, which is essential for species identification.

Our results proved that the application of micro-CT device in palaeontological research can replace some of those investigations which require difficult professional aptitudes (skill, routine and time).

This visualization technique gives new perspectives in taxonomical studies of unique specimens, species bearing characteristic internal structure or which are known only from thin sections. In addition, it increases the efficiency of the cuttings studies in drilling geology.

\section{ACKNOWLEDGMENTS}

The authors would like to sincerely thank M. Kovács and Cs. Dobó Nagy (Semmelweis University, Budapest) for their help in using the micro-CT device, T. Földes (Tomo Geo Kft., Szolnok) for the consultations on CT technology and to J. Pálfy (MTA-ELTE, Budapest) and R. Wernli (University of Geneva) for their helpful advices. Thanks to R. Pitt and J.-M. Jaquet, who greatly improved the English. J. Fábián-Lukács (Praxis pro Aqua, INNO-52006-0022, OMFB-0147/2006), OTKA (68791) and Hantken Foundation are acknowledged for the financial support.

E. Tóth is thankful for the contribution of HASHNHM Research Group for Paleontology (Paleocontribution No. 147.).

\section{REFERENCES}

Briguglio, A. 2010. Hydrodynamic behaviour of nummulitids. Unpublished PhD Thesis, Universität Wien, Austria. http://othes.univie.ac.at/12131/1/2010-1108_0749105.pdf

Burrow, C.J., Jones, A.S., and Young, G.C. 2005. X-ray microtomography of 410 million-year-old optic capsules from placoderm fishes. Micron, 36:551-557.

Claessens, L.P.A.M., O'Connor, P.M., and Unwin, D.M. 2009. Respiratory evolution facilitated the origin of pterosaur flight and aerial gigantism. PLOS ONE, 4(2):e4497. doi:10.1371/journal.pone.0004497. 
Dierick, M., Cnudde, V., Masschaele, B., Vlassenbroeck, J., Van Hoorebeke, L., and Jacobs, P. 2007. MicroCT of fossils preserved in amber. Nuclear Instruments and Methods in Physics Research Section A: Accelerators, Spectrometers, Detectors and Associated Equipment, Proceedings of the 10 th International Symposium on Radiation Physics - ISRP 10, 580(1):641-643.

d'Orbigny, A. 1839. Foraminifères, p. 1-224. In de la Sagra, R. (ed.), Histoire physique, politique et naturelle de l'île de Cuba. Arthus Bertrand, Paris, 8.

Hay, W.W. and Sandberg, P.A. 1967. The scanning electron microscope, a major break-through for micropaleontology. Micropaleontology, 13:407-418.

Heethoff, M., Helfen, L., and Norton, R.A. 2009. Description of Neoliodes dominicus n. sp. (Acari, Oribatida) from Dominican Amber, aided by synchrotron x-ray microtomography. Journal of Paleontology, 83:153159.

Loeblich, A.R. and Tappan, H. 1988. Foraminiferal Genera and Their Classification. Van Nostrand Reinhold, New York, 2 vols.

Łuczkowska, E. 1972. Miliolidae (Foraminiferida) from Miocene of Poland, part I. Revision of the classification. Acta Palaeontologica Polonica, 17:341-377.

Łuczkowska, E. 1974. Miliolidae (Foraminiferida) from Miocene of Poland, part II. Biostratigraphy, Palaeoecolgy and Systematics. Acta Palaeontologica Polonica, 19:1-176.

Mees, F., Swennen, R., Van Geet, M., and Jacobs, P. 2003. Applications of x-ray computed tomography in the geosciences. Geological Society, London, Special Publication 215.

Monnet, C., Zollikofer, C., Bucher, H., and Goudemand, N. 2009. Three dimensional morphometric ontogeny of mollusc shells by micro-computed tomography and geometric analysis. Palaeontologia Electronica, 12(3), 12A:1-13.

Paalzow, R. 1917. Beiträge zur Kenntnis der Foraminiferen fauna der Schwammergel des Unteren Weissen Jura in Süddeutschland. Abhandlungen der Naturhistorischen Gesellschaft zu Nürnberg, 17:201249.

Pakhnevich, A.V. and Bryantseva, A. 2007. Studying of fossil invertebrates for example brachiopods by using of the X-ray micro-CT SkyScan 1172. SkyScan User Meeting 2007, Abstract, http://www.skyscan.be/company/usersmeeting2007.htm (2010-03-21)

Penney, D., Dierick, M., Cnudde, V., Masschaele, B., Vlassenbroeck, J., Van Hoorebeke, L., and Jacobs, P. 2007. First fossil Micropholcommatidae (Araneae), imaged in Eocene Paris amber using $\mathrm{x}$-ray computed tomography. Zootaxa, 1623:47-53.

Reuss, A.E. 1844. Geognostische Skizzen aus Böhmen. II. Theil- Die Kreidegebilde des westlichen Böhmens. C.W. Medau \& Comp, Prag.
Reuss, A.E. 1850. Neue Foraminiferen aus den Schichten des Österreichischen Tertiärbeckens. Denkschriften der Akademie der Wissenschaften, Wien, Mathematisch-Naturwissenschaftliche Klasse, 1:365390.

Rossi, M., Casali, F., Romani, D., Bondioli, L., Macchiarelli, R., and Rook, L. 2004. MicroCT Scan in paleobiology: application to the study of dental tissues. Nuclear Instruments and Methods in Physics Research B, 213:747-750.

Schönberg, C.H.L. and Shields, G. 2008. Micro-computed tomography for studies on Entobia: transparent substrate versus modern technology, p.147-164. In Wisshak, M. and Tapanila, L. (eds.), Current Developments in Bioerosion. Erlangen Earth Conference Series, Springer-Verlag, Berlin, Heidelberg.

Schmidt, R.A.M. 1952. Microradiography of microfossils with X-ray diffraction equipment, Science, 115 (1952):94-95.

SkyScan 2005. SkyScan 1172. Desktop X-ray Microtomograph. Instruction Manual. http://www.itg.uiuc.edu/ help/microct/1172_Manual.pdf (2010-03-21)

Speijer, R.P., Van Loo, D., Masschaele, B., Vlassenbroeck, J., Cnudde, V., and Jacobs P. 2008. Quantifying foraminiferal growth with high-resolution x-ray computed tomography: New opportunities in foraminiferal ontogeny, phylogeny, and paleoceanographic applications. Geosphere; 4:760-763.

Stock, S.R., Ignatiev, K.I., Dahl, T., Veis, A., and De Carlo, F. 2003a. Three-dimensional microarchitecture of the plates (primary, secondary, and carinar process) in the developing tooth of Lytechinus variegatus revealed by synchrotron $\mathrm{x}$-ray absorption microtomography (microCT). Journal of Structural Biology, 144:282-300.

Stock, S.R., Nagaraja, S., Barss, J., Dahl, T., and Veis, A. 2003b. X-ray microCT study of pyramids of the sea urchin Lytechinus variegatus. Journal of Structural Biology, 141:9-21.

Strickland, H. E. 1846. On two species of microscopic shells found in the Lias. Quarterly Journal of the Geological Society, 2:30-31.

Szinger B., Görög Á., Tóth, E., and Viszkok, J. 2007. Mikro-CT alkalmazása, mint új lehetőség az őslénytani kutatásban, p. 34-35. In Pálfy, J., Bosnakoff, M., and Pazonyi, P. (eds.), 10. Program, elöadáskivonatok, kirándulásvezető. Magyar Őslénytani Vándorgyülés, 2007. május 24-26. Budapest (In Hungarian)

Tapanila, L. 2008. The medium is the message: imaging a complex microboring (Pyrodendrina cupra igen. $\mathrm{n}$., isp. n.) from the early Paleozoic of Anticosti Island, Canada, p. 123-145. In Wisshak, M. and Tapanila, L. (eds.), Current Developments in Bioerosion. Erlangen Earth Conference Series, Springer-Verlag, Berlin, Heidelberg. 
von Fichtel, L. and von Moll, J.P.C. 1798. Testacea microscopica, aliaque minuta ex generibus Argonauta et Nautilus, ad naturam picta et descripta (Mikroskopische und andere kleine Schalthiere aus den Geschlechtern Argonaute und Schiffer nach der Natur gemahlet und beschrieben). Gedruckt bei Anton Pichler, Wien. 